\title{
Infrared thermography used to analyze the effects of crystallization process in Al alloys
}

\author{
by R. Władysiak*, A. Kozuń* and T. Pacyniak*
}

* Lodz University of Technology, Department of Materials Engineering and Production Systems,

1/15 Stefanowskiego Str., 90-924 Lodz, Poland, ryszard.wladysiak@p.lodz.pl

\begin{abstract}
This paper describes the application of thermography for analysing the phases forming during the crystallization process of casting alloys. The study was conducted for aluminium alloys with use of Crystaldigraph PC, infrared camera PI OPTRIS 160. Research findings were also verified with analysis of the microstructure of samples obtained in ATD probe. The work demonstrates that the use of thermal imaging camera allows for dynamic measurement and recording the solidification process of $\mathrm{Al}-\mathrm{Si}$ alloys. The thermal curve generated by the camera software corresponds to the equilibrium phase diagram, the specific temperature values and the microstructure of aluminium alloys.
\end{abstract}

Keywords: Dynamic thermography, Thermal and Derivative Analysis, Metallurgical applications

\section{Introduction}

This work is a part of research into the improvement of thermal and derivative analysis (TDA) in research the solidification process of metals and alloys. The paper presents the possibility of implementing TDA with a thermal imaging camera. The theoretical basis of TDA methods for metals and alloys including Al-Si alloys developed S. Jura [1]. At the turn of the last few years, this method is still developing. New types of probes have been developed, new basic software of the methods as well as new control algorithms. This expands its application to the study of new types of metal materials [2-7].

According to them, thermal and derivative analysis is carried out by an apparatus Crystaldigraph and a ceramic probe (e.g. ATD-10) with the thermocouple type $\mathrm{K}$ or $\mathrm{S}$ placed in the middle of the heat of sample area. In the TDA method are recorded two curves: cooling $t=f(\tau)$ and crystallization $t{ }^{\prime}=d t / d \tau=f^{\prime}(\tau)$. Crystallization phases during cooling of the melt causes specific for sample alloy stops of temperature on thermal curve reflected clear thermal effects (peaks and humps) on the derivative curve. Interpretation of shape and characteristic point values of the two TDA curves allows the analysis of the solidification and crystallization process and evaluate the quality of prepared, the liquid alloy casting.

Temperature measurement in the TDA method uses a thermocouple that is the basis for the calculation and registration of the curves. Its operation is based on the phenomena of occurrence of the point of connection of two different metals of the electromotive force, the magnitude of which depends on the temperature of the connector. This phenomenon has been noted and explained in the nineteenth century by Seebeck, Peltier and Thomson [8].

Currently, thermography is a very fast growing method allowing to track various processes that cause fixed and variable temperature field. The essence of the method is the assumption that all of the solids, liquids and gases whose temperature is higher than absolute zero $(0 \mathrm{~K})$ emit radiation with an energy dependent on temperature and wavelength of radiation [9].

Infrared thermography involved in detection, registration, processing and visualization of invisible infrared light (heat) emitted by the tested object. An essential element of modern infrared cameras is microbolometer infrared detector. Converting a photon energy of infrared radiation into an electrical signal. The value of the received signal depends directly on the temperature of the object, lens type, size and resolution matrix detector. These modern cameras work with a high resolution matrix of and an advanced methods of reading infrared amplification, the current-voltage conversion (IU) and a correction of heterogeneity signal. It means that infrared cameras enable to record the high-resolution temperature field at several tens $\mathrm{mK}$ and frequency measurement order of $10^{2} \mathrm{~Hz}$ [10]. These features fulfill particular requirements for analysis alloys that solidified with rapid crystallization process as a result of intensive cooling of cast.

\section{Instrumentation and Measurement Procedures}

The research was conducted on at the station, which schematically was shown in Figures 1 and 2 . The first station (Fig.1) is equipped with a resistive melting furnace to prepare the liquid metal, Crystaldigraph PC (U/f converter + software) manufactured by Z-TECH, infrared camera PI OPTRIS 160, the probe ATD-10 shown in Figure $1 \mathrm{~b}$, is made of high-silica sand and optionally equipped with a quartz glass piece. Microstructure of the samples was performed using a Nikon microscope MA200. The research of solidification process of the silumin was carried out simultaneously by Crystaldigraph in the sampler ATD-10 and with use of infrared camera. During the tests the temperature measurement and recording of solidifying the sample of silumin performed using thermocouple $\mathrm{S}(\mathrm{PtRh} 10-\mathrm{Pt})$ and by observation of the 
free surface of the metal sample - in the first variant and with use the quartz piece - in the second variant. The tests were performed for synthetic Al-Si alloys that chemical compositions are shown in Table 1.

Investigations of rapid solidification of silumin were conducted at station 2 (Fig. 2). High cooling rate was achieved by the use of the metallic probe (Figure 2, point 10) having a wall thickness of $2 \mathrm{~mm}$ which was cooled by stream of water mist. The probe was equipped with the quartz glass piece (Fig. 1b). The computer (Fig. 2, points 7.8) was used to control the production of water mist, cooling probe and handle the thermal imaging camera of thermographic analysis stand (10) and also it recorded the temperature of small sample of solidifying metal.

a)

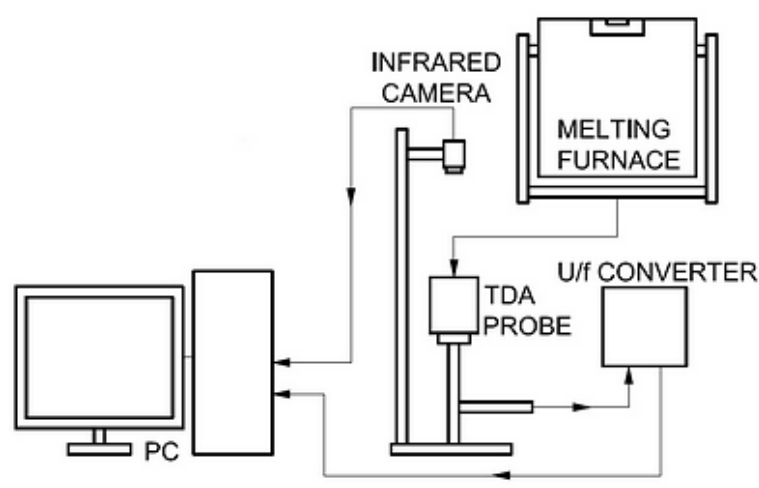

b)

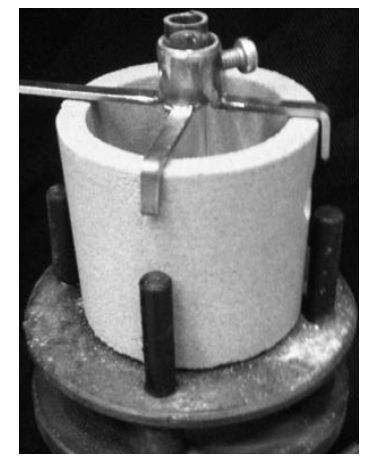

Fig. 1. Scheme of research station (a) and view of ATD-10 probe with quartz glass piece (b)

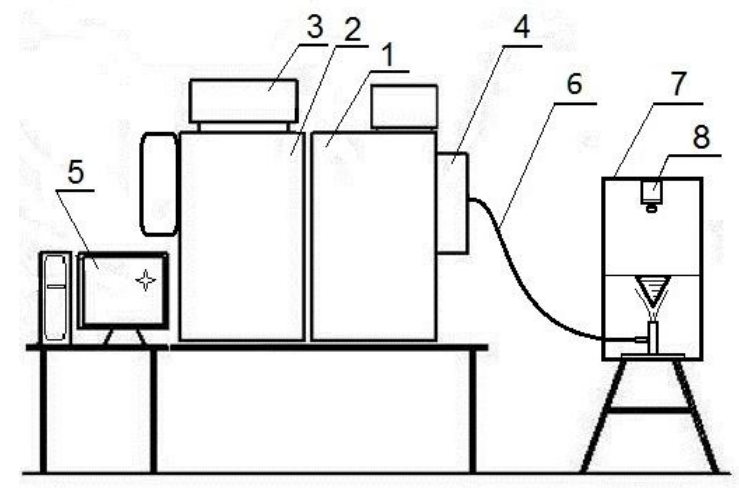

Fig. 2. The scheme of the research station: 1, 2- air and water dosing modules, 3-computer control of cooling, 4-mixing module, 5-PC, 6- cooling circuit, 7-thermographic analysis stand, 8 - Infrared camera

Table 1. Chemical composition of alloys

\begin{tabular}{|c|c|c|c|c|c|c|c|c|c|}
\hline \multirow{2}{*}{ Alloy } & \multicolumn{10}{|c|}{ Chemical composition, weight \% } \\
\cline { 2 - 11 } & $\mathrm{Si}$ & $\mathrm{Mg}$ & $\mathrm{Cu}$ & $\mathrm{Mn}$ & $\mathrm{Fe}$ & $\mathrm{Ti}$ & $\mathrm{P}$ & $\mathrm{B}$ & $\mathrm{Al}$ \\
\hline AlSi8 & 7.81 & 0.024 & 0.034 & 0.132 & 0.276 & 0.007 & - & - & rest \\
\hline AlSi19 & 19,36 & 0,012 & 0,010 & 0,005 & 0,159 & 0,0036 & 0,0018 & 0,0062 & rest \\
\hline
\end{tabular}

\section{Results}

The research was conducted with using hypo- and hypereutectic silumins AISi8 i AISi19. In its composition is dominated by two elements, aluminum and silicon, wherein the silicon content may range from about $7 \div 19 \%$. Basic reference of the subject demonstrates that the microstructure of the silumin group occurs only or in a predominant amount, eutectic $\alpha+\beta(\mathrm{Al}+\mathrm{Si})$. In the neareutectic silumin which has a much greater range of the solidification temperature, there is a additionally preeutectic crystallization of dendrites $\alpha$ (Al). The amount of phases depends on the speed of growth, temperature gradient and chemical composition, which define the size and shape of thermal effects (stops) on thermal curve and piks or humps on the derivative curve.

Figure $3 a$ shows the display screen with the selected thermographic test results using a thermal imaging camera, the surface area of the free silumin AISi8 solidifying in the sampler ATD-10. Figure includes a plot of the maximum 
temperature at the time of the free surface area of the "Area 1", the thermogram of the sample surface, the strip temperature and the reference histogram temperature distribution with the mean value and standard deviation of this distribution. The study also analyzed the value of the maximum temperature in the fields "Area 1", "Area 2" and "Area 3" with dimensions reduced to a few pixels. Figure $3 b$ shows comparison obtained by using the process imager software. The presented data show that the used camera enables detailed analysis of the sample temperature field and its changes during the cooling process.

a)

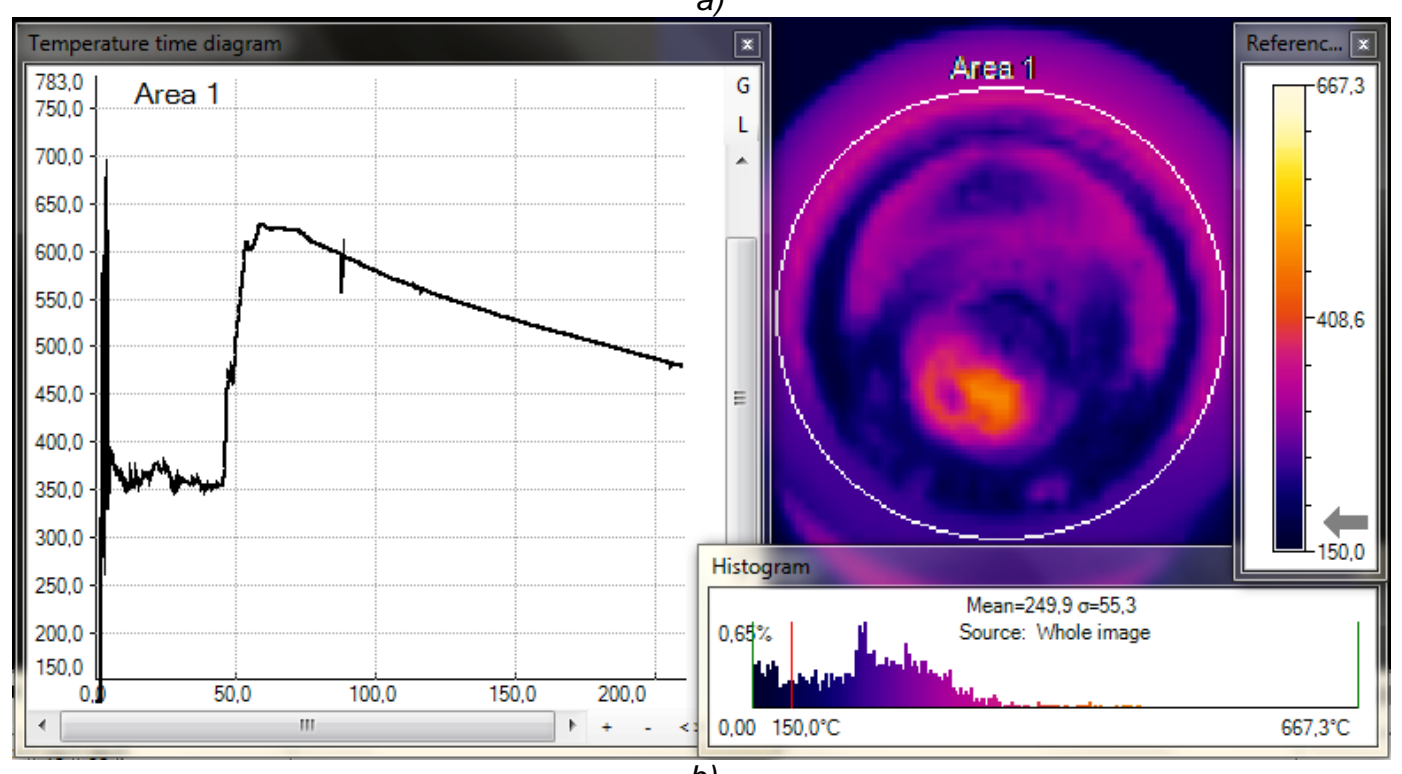

b)

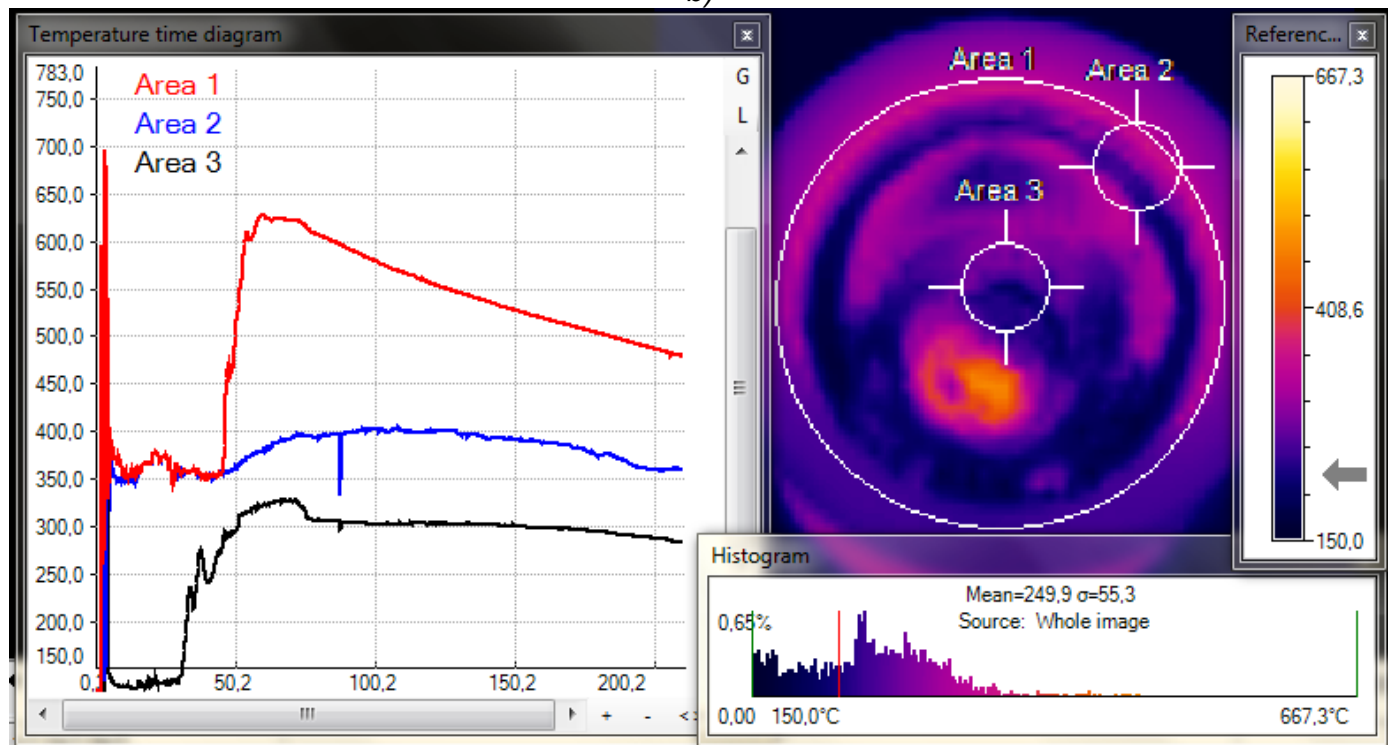

Fig. 3. Temperature (Celsius) time (second) diagrams, thermograms and histograms of the temperature distribution on the surface of AlSi8 alloy sample obtained by using the process imager software of the infrared camera. The temperature time diagram is reading as maximum of all free surface of sample (a) and otherwise as a comparison of temperature in areas 1, 2 (5x5 pixel) and 3 (b).

The results recorded in this way the temperature $t=f(\tau)$ and the calculated derivative $t{ }^{\prime}=d t / d \tau=f^{\prime}(\tau)$ for silumin AISi8 shown in Figure 4. The research shows that in the initial stage there is a rapid cooling of the temperature drop, which is caused by the reaction of the liquid metal with the air and changes: physical state, roughness and shape of the surface layer of the sample. These changes cause a change in emissivity of the sample surface, the test surface by lowering the temperature to about $376^{\circ} \mathrm{C}$. In the next part of research the crystals of Al phase nucleate and grow preeutectically (Fig. 4: range $\mathrm{AC}$ ) and after that the eutectic $\mathrm{Al}+\mathrm{Si}$ crystallizes (Fig. 4, the range CF). As a result of emission of a latent heat from the crystallizing phases, the temperature of the entire metal sample, including the sample surface increases to $571^{\circ} \mathrm{C}$. 
The analysis of the derivative curve (Fig. 4: $d t / d \tau=f^{\prime}(\tau)$ ) shows that measure the surface temperature of the sample reflects the nature of the thermal processes taking place in the silumin, although the temperature and volume of the thermal effects do not correspond to the changes occurring within the sample solidifying metal.

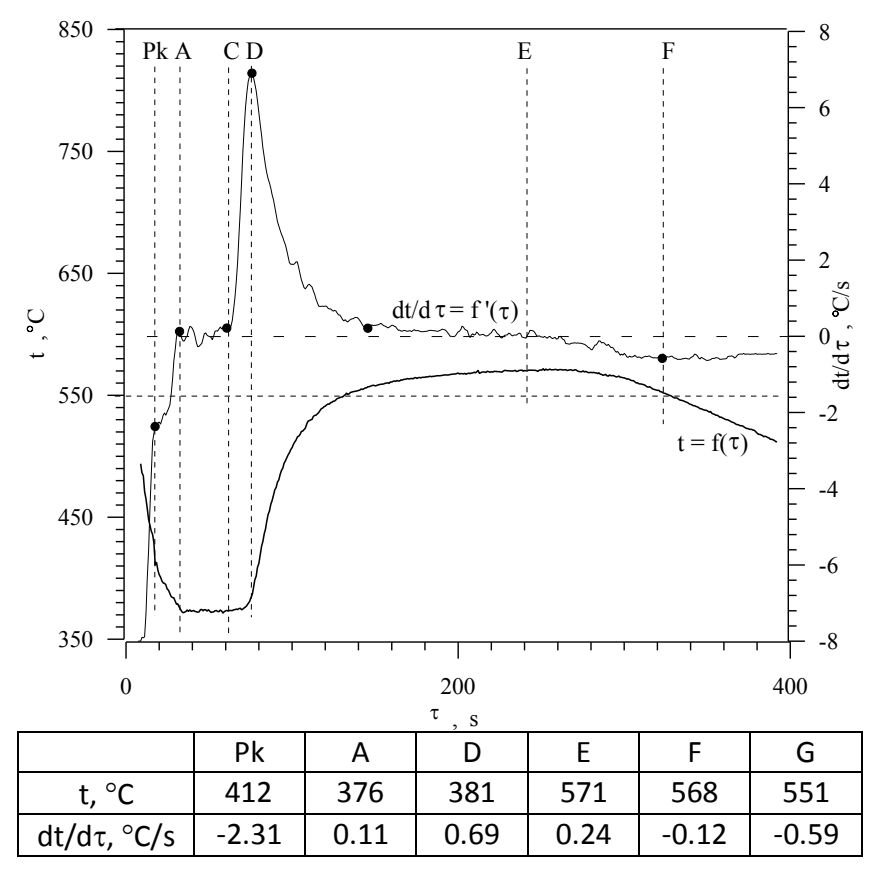

Fig. 4. Thermal and derivative curves and specific values of solidification process of AlSi8 alloy using the thermographic method

In order to observe the thermal changes of silumin in the middle of a heat probe were applied the probes with the quartz piece (Fig. 1 b). Figure 5 shows the thermograms of the AISi8 alloy in solidification process using a probe with the quartz piece. Figure 6 presents the temperature (Celsius) versus time (second) diagram generated by the camera software while being getting cold and solidifying of the alloy sample. The microstructure (Fig. 6 b) contents phase $\alpha$ (Al, white field) and eutectic $\alpha+\beta(\mathrm{Al}+\mathrm{Si})$.

The research shows that the temperature field defined by this way is characterized by high homogeneity and stability of indications. Enhancing the quality of measurements of temperature values has a positive effect on the quality of the cooling curve and the results of the derivative curve calculation.

Curves and specific values in Figure $7(a, b)$ let to compare the temperature data of AISi8 alloy obtained by TDA and the thermographic methods. In both cases, the probe was made of high-silica sand and possess with the quartz glass piece. The analysis of the chemical composition and microstructure observation of the alloy shows that the solidification starts from the nucleation of aluminum. The maximum thermal effect is reflected in the form of a clear peak with a maximum cooling rate $\mathrm{dt} / \mathrm{d} \tau=0.37^{\circ} \mathrm{C} / \mathrm{s}$ at $\mathrm{A}$ at the temperature $\mathrm{t} A=609^{\circ} \mathrm{C}$. In the micro-regions remaining liquid around the dendrites of aluminum the silicon concentration increases. After supercooling of the liquid below the eutectic transition temperature $\mathrm{tC}=581^{\circ} \mathrm{C}$, silumin enter into a zone of coupled growth of eutectic. In the CDEF range the irregular lamellar eutectic crystallizes. This process is stabilized at $\mathrm{tE}=582^{\circ} \mathrm{C}$. Crystallization of the silumin ends at $\mathrm{tF}=$ $524^{\circ} \mathrm{C}$.

The study shows that the cooling curves obtained from infrared camera have a course similar to the curves obtained by the TDA classical method of temperature measurement with use the thermocouple type S (PtRh10-Pt). In addition, they suggest that the definition of analyzed temperature fields using the quartz piece placed in the middle of the heat eliminates the problems caused by phenomena occurring on the free surface of the metal.

In Figures 8 and 9 have shown, respectively, the temperature time diagram, thermogram and histogram of the temperature distribution on the surface "Area 1" of hypereutectic alloy AISi19 sample during the test of rapid solidification and representative curves - thermal and derivative of (Fig. 9 a) obtained by thermographic method. Analysis of the alloy solidification was conducted with cooling of metallic probe by the water mist stream.

The crystallization of hypereutectic silumins starts from the initial crystallization of silicon crystals, that occur in alloy microstructure (Fig. 9 b). The beginning of the crystallization presents the point Pk in TDA curves. The temperature of AISi19 is $t_{P k}=649 \mathrm{C}$. This point is a local minimum value in derivative curve $\mathrm{dt} / \mathrm{d} \tau=-41.2 \mathrm{C} / \mathrm{s}$.

It follows in that emitted heat of crystallization preeutectic crystallization of crystals Si ( $\beta$ phase) cause the heating up of the alloy from $P k$ to $A^{\prime}\left(t_{A^{\prime}}=587 \mathrm{C}\right)$ and decrease of cooling rate to $d t / d \tau=-4.2 \mathrm{C} / \mathrm{s}$.

The concentration of silicon in the liquid around the large crystals of $\beta$ decreases creating favorable conditions for nucleation of $\alpha$ phase on the existing silicon crystals. On the crystallization curve it manifests probably the result of heat from the crystallization of a phase dendrites. Farther lowering the temperature causes the silumin enter into a zone of 


\subsection{1/qirt.2016.151}

eutectic coupled growth and in terms of irregular eutectic CDEF crystallized lamellar $\alpha+\beta(\mathrm{Al}+\mathrm{Si})$ at the temperature $\mathrm{t}_{\mathrm{c}}$ $\mathrm{E}=565 \div 557 \mathrm{C}$. In the microstructure of AISi19 alloy was observed changes in the process of solidification as a result of application the water mist cooling of the probe. The liquid metal is high overcooling because the cooling rate increase to $\mathrm{dt} / \mathrm{d} \tau=-41.2 \mathrm{C} / \mathrm{s}$.

a)

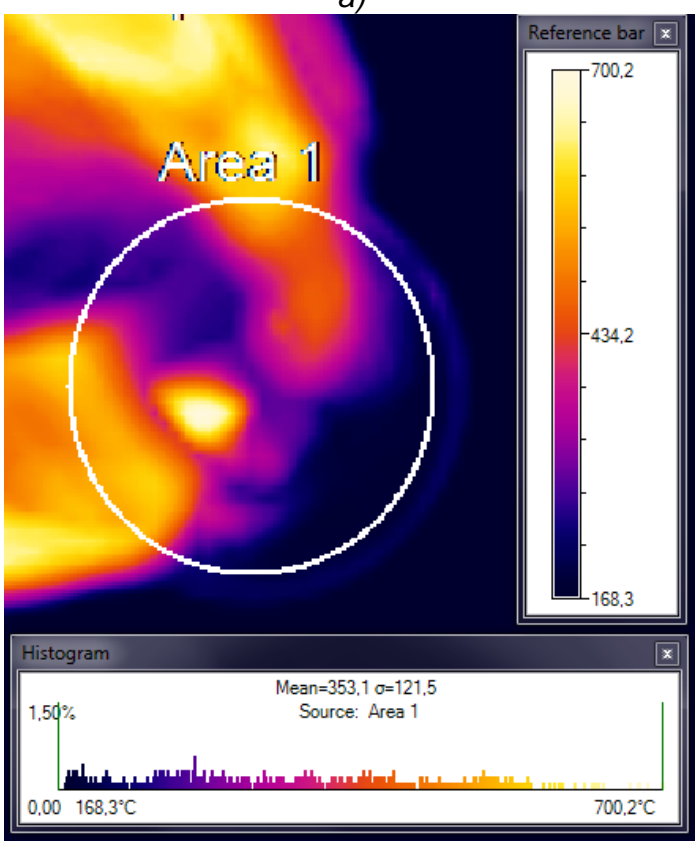

c)

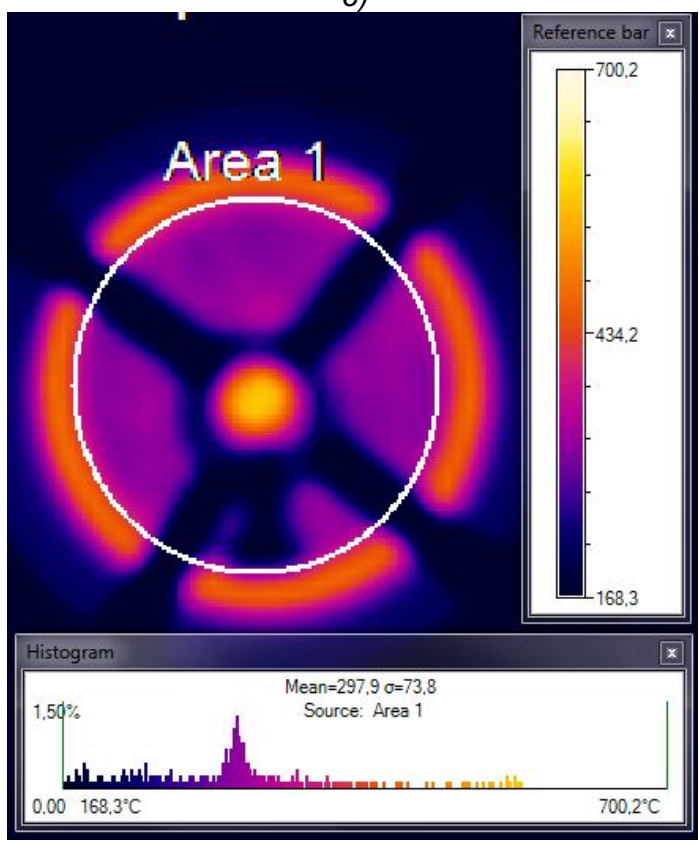

b)

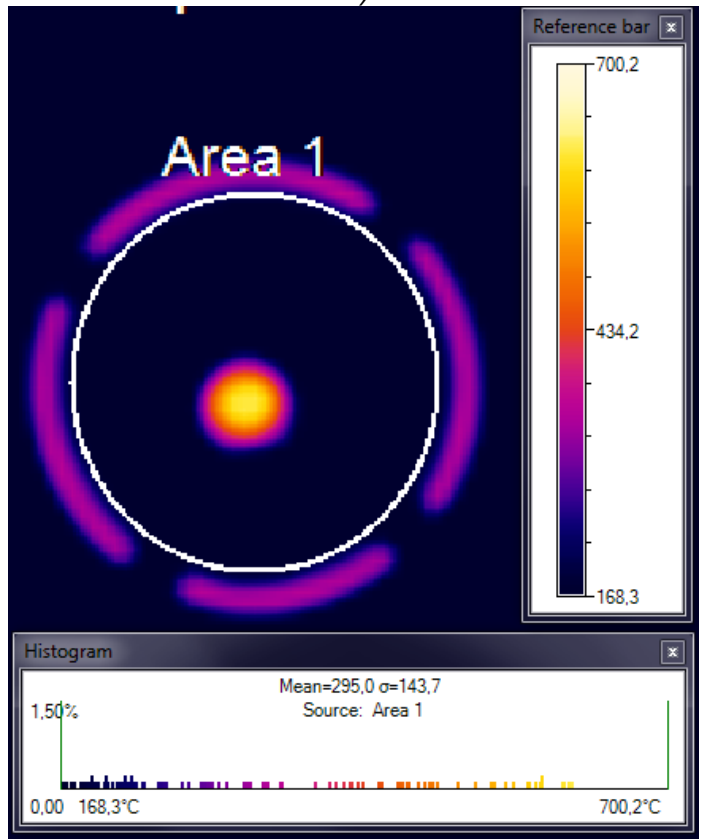

d)

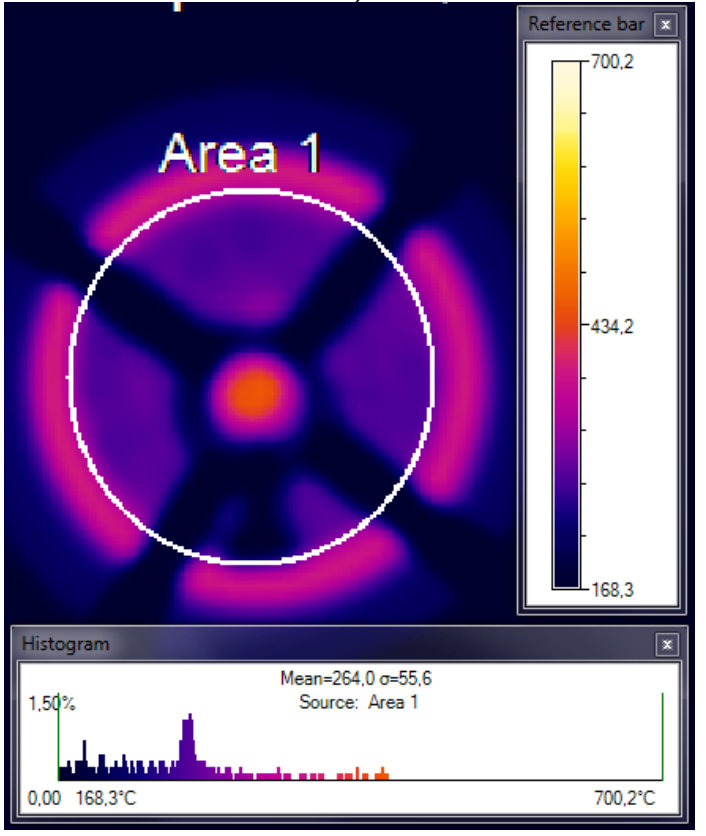

Fig.5. Thermograms and histograms of the temperature distribution on the surface "Area 1" of AlSi8 alloy during the test in silica-sand probe with quartz piece: a) pouring liquid metal into the probe (time: 54 second in Fig. 2), b) $-81 s, c)-352 s, d)-670 s$ 


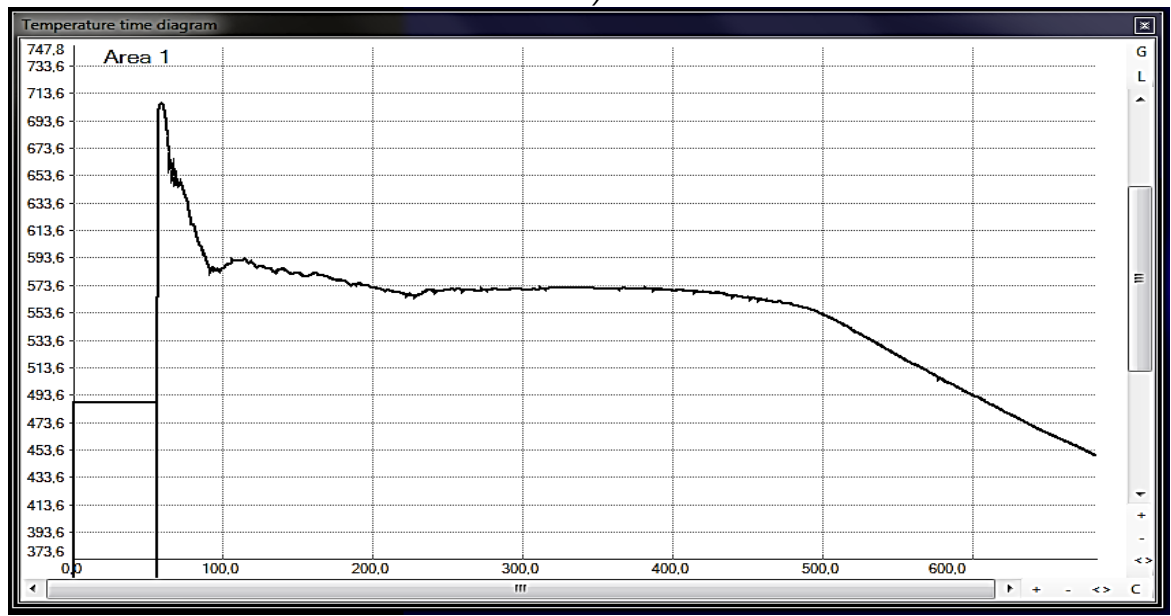

b)

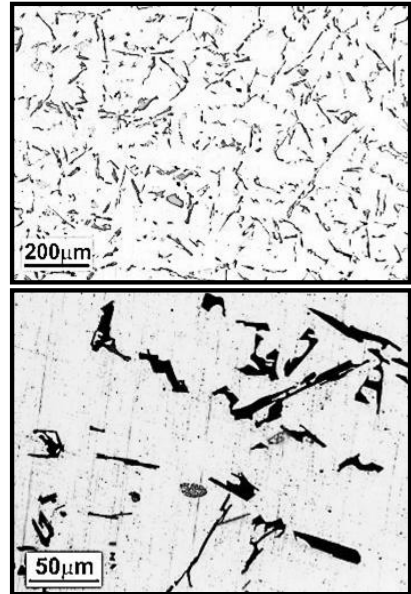

Fig. 6. Temperature (Celsius) versus time (second) diagram generated by the camera software while being getting cold and solidifying of the AISi8 alloy sample (a) in silica-sand probe with quartz piece, microstructure (b): phase $\alpha(A l)$, eutectic $\alpha+\beta(A l+S i)$

a)

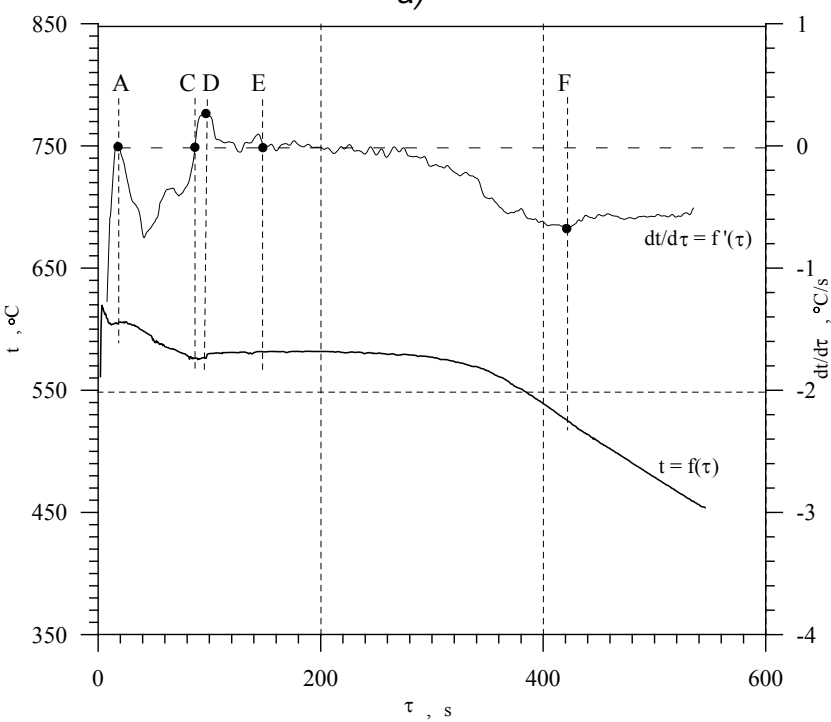

\begin{tabular}{|c|c|c|c|c|c|}
\hline & A & C & D & E & F \\
\hline $\mathrm{t},{ }^{\circ} \mathrm{C}$ & 606 & 577 & 575 & 581 & 524 \\
\hline $\mathrm{dt} / \mathrm{d} \tau,{ }^{\circ} \mathrm{C} / \mathrm{s}$ & 0.08 & 0 & 0.28 & 0 & -0.78 \\
\hline
\end{tabular}

b)

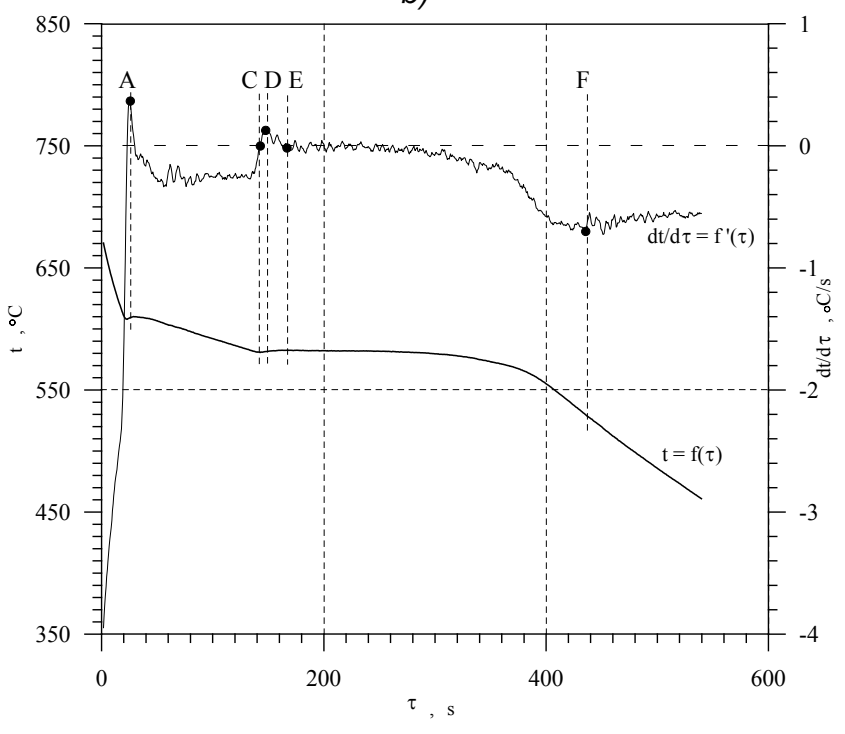

\begin{tabular}{|c|c|c|c|c|c|}
\hline & A & C & D & E & F \\
\hline $\mathrm{t},{ }^{\circ} \mathrm{C}$ & 609 & 581 & 580 & 582 & 524 \\
\hline $\mathrm{dt} / \mathrm{d} \tau,{ }^{\circ} \mathrm{C} / \mathrm{s}$ & 0.37 & 0 & 0.10 & 0 & -0.69 \\
\hline
\end{tabular}

Fig. 7. Thermal and derivative curves and specific values of solidification process of AlSi8 alloy obtained by the thermographic method (a) and by TDA method (b) using the silica-sand probe with quartz piece

In summary, the studies demonstrate that the use of thermal imaging camera allows for the measurement and recording of cooling and solidification process of silumins. Thermal curves and calculated on the basis the derivative curve have a very similar shape to the curves of TDA obtained from the thermocouple measurements. Results of studies by TDA thermographic method allow quantitative analysis of the cooling process kinetics of hypoeutectic silumin and neareutectic as well. 


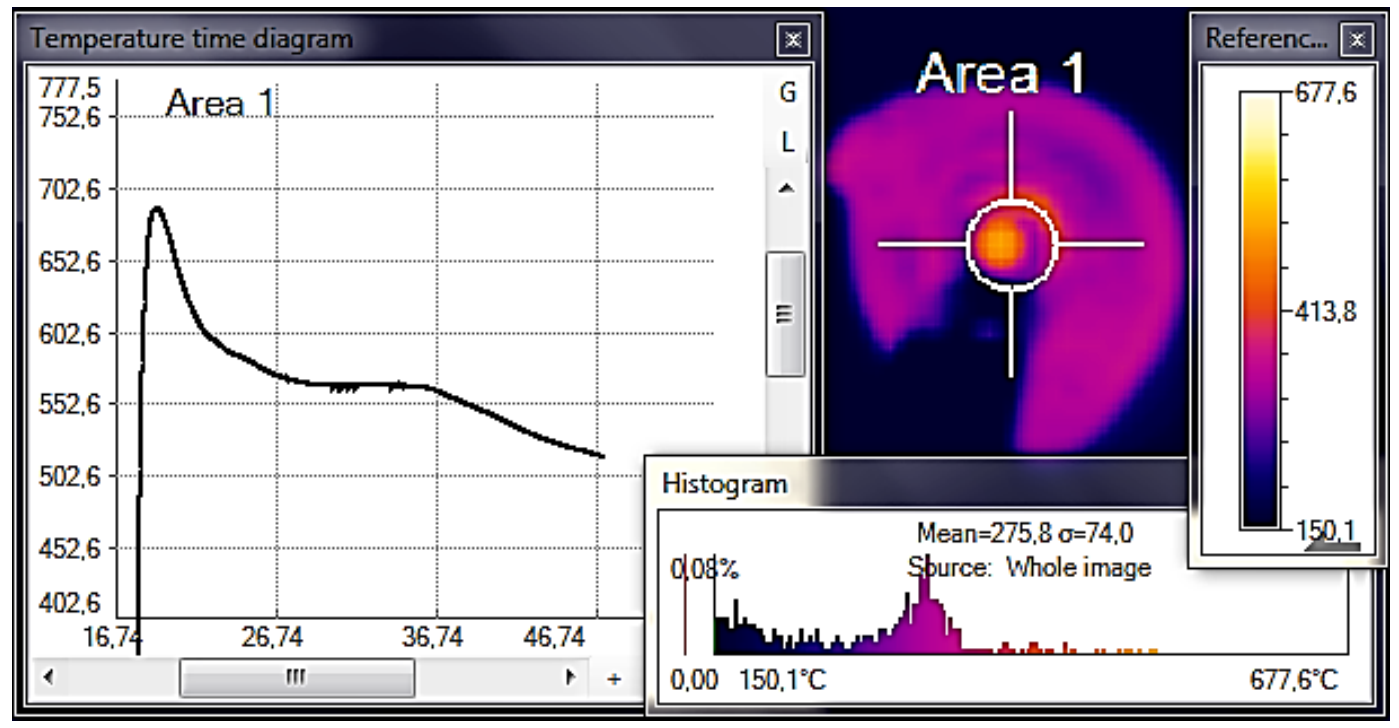

Fig. 8. Temperature (Celsius) time (second) diagram, thermogram and histogram of the temperature distribution on the surface "Area 1"of AlSi19 alloy sample during the test of rapid solidification

a)

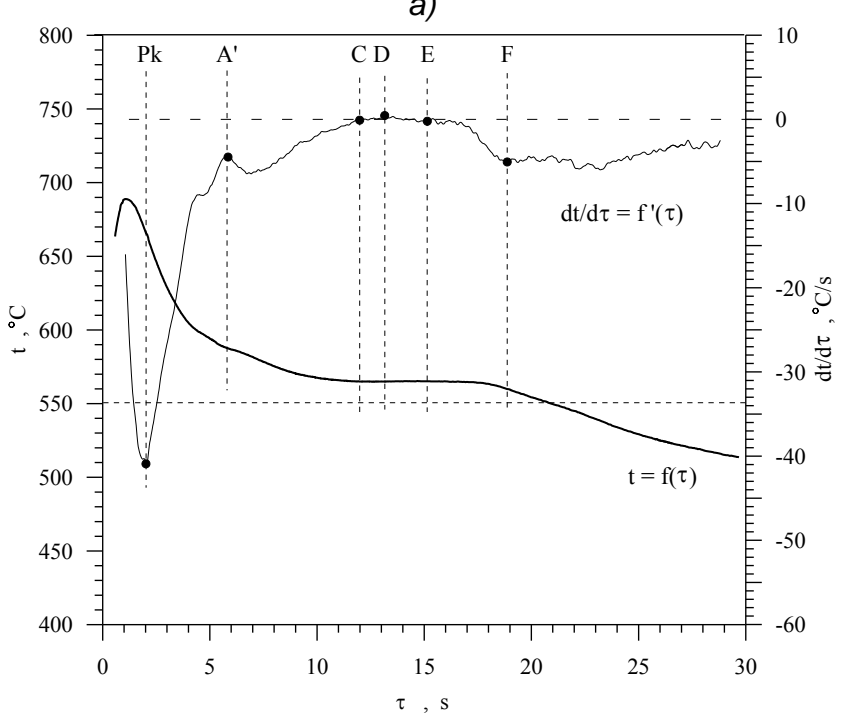

\begin{tabular}{|c|c|c|c|c|c|c|}
\hline & $\mathrm{Pk}$ & $\mathrm{A}^{\prime}$ & $\mathrm{C}$ & $\mathrm{D}$ & $\mathrm{E}$ & $\mathrm{F}$ \\
\hline$\tau, \mathrm{s}$ & 2,24 & 6,02 & 12,08 & 13,26 & 15,22 & 19,24 \\
\hline $\mathrm{t}, \mathrm{C}$ & 648,7 & 587 & 564,8 & 565,2 & 565,4 & 557 \\
\hline $\mathrm{dt} / \mathrm{d} \tau, \mathrm{C} / \mathrm{s}$ & $-41,2$ & $-4,2$ & 0 & 0,6 & 0 & $-5,5$ \\
\hline
\end{tabular}

b)

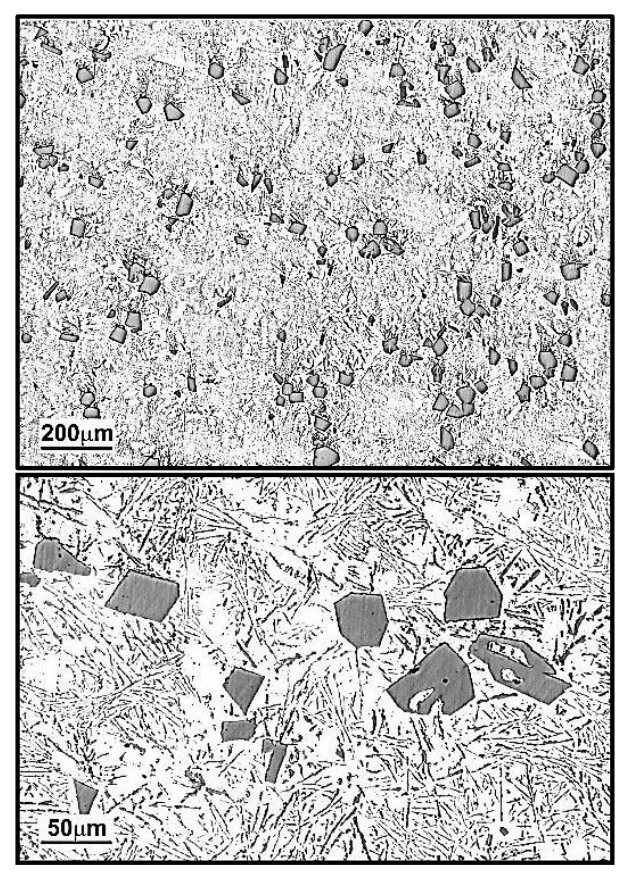

Fig. 9. Thermal and derivative curves of solidification process (a) and microstructure (b) of AlSi19 alloy obtained by the thermographic method (a) using the metallic probe with quartz piece and with water mist cooling of the probe 


\section{Conclusions}

The study shows that:

- $\quad$ thermographic method provides a quantitative analysis of kinetics of cooling and solidification process of hypoand hypereutectic Al-Si alloys,

- $\quad$ tested methods of analysis the solidification process have similar values of the temperature and cooling rate at characteristic points of the process,

- $\quad$ analysis of the temperature field of free surface sample reflects the stages of solidification process occurring in the silumin,

- $\quad$ high measurement frequency of thermal imaging camera allows to analyse the rapid solidification of alloys.

\section{REFERENCES}

[1] Jura S., Jura Z.: (1996). The Theory of ATD Method in the Study of Al Alloys. Solidification of Metals and Alloys. Polish Academy of Sciences - The Katowice Branch Commission of Foundry Engineering, 1996, vol. 28. , s. 57. (Polish)

[2] Pietrowski S., Pisarek B., Władysiak R. (1998): Alloy Cast Iron with Vermicular Graphite. Solidification of Metals and Alloys. Polish Academy of Sciences - The Katowice Branch, Commission of Foundry Engineering, 1998, vol. 37, s. 105. (Polish)

[3] R. Władysiak: Austenitic Cast Iron Control by ATD Method. Archives of Foundry, Polish Academy of Sciences The Katowice Branch, Commission of Foundry Engineering, 2001, vol. 1, No. 1 (2/2), s. 400-407 (Polish)

[4] Pietrowski S. (2001). Silumins, LUT Publishing House, Lodz (Polish)

[5] Pietrowski S., Gumienny G., Pisarek B., Władysiak R. (2005): Monitoring of Production and Quality Control of Casting Alloys with Use of ATD Methods. Archives of Foundry, Polish Academy of Sciences - The Katowice Branch, Commission of Foundry Engineering, 2005, vol.5, No. 15, s. 310-328

[6] Rapiejko, C., Pisarek, B., Czekaj, E. \& Pacyniak, T. (2014). Analysis of the Crystallization of AZ91 Alloy by Thermal and Derivative Analysis Method Intensively Cooled in Ceramic Shell. Archives of Foundry Engineering. 14(1), 97-102

[7] Władysiak R. (2013). Examining the Possibilities of Analyzing the Solidification Process of Al-Si Alloy with the Infrared Camera. Archives of Foudry Engineering. 16(1), 89-94

[8] Michalski L., Eckersdorf K. (1986): The temperature measurements. WNT, 1986. (Polish)

[9] Więcek B., De Mey G. (2011): Infrared Thermovision. Fundamentals and Applications, PAK Publishing House, Warsaw 2011. (Polish)

[10] Orżanowski T., Madura H., Powiada E., Pasierbiński J. (2006): Analysis of the Reading to the Microbolometer Detector Matrix, Measurement Inspection Automation, No. 9, 2006. (Polish) 